\title{
SOBRE EL MODELO DE APRECIACIÓN DE ABUSIVIDAD EN LA LEY No 19.496, CON ESPECIAL REFERENCIA A SU ARTÍCULO 16 LETRA G). BASES PARA UNA DIFERENCIACIÓN ENTRE EL CONTROL DE CONTENIDO Y EL DE SORPRESIVIDAD
}

\author{
ABOUT THE MODEL OF UNFAIRNESS ASSESSMENT IN THE No 19.496 \\ LAW, WITH SPECIAL REFERENCE TO ITS ARTICLE 16 LETTER G). \\ BASES FOR ESTABLISHING DIFFERENCES BETWEEN CONTENT \\ CONTROL AND CONTROL OF SURPRISING TERMS
}

\author{
Sebastián Nicolás Campos Micin ${ }^{*}$
}

\begin{abstract}
RESUMEN: A la luz de los modelos presentes en el derecho alemán y la Directiva 93/13/ CEE, se analiza el modelo de apreciación de abusividad que establece el artículo 16 letra g) de la ley No 19.496. Se explica cómo parte de nuestra doctrina y jurisprudencia acercan el control de contenido al de sorpresividad. Se aduce que esta aproximación entraña el riesgo de desvirtuar el control de contenido, justificando la validez de cláusulas que, pese a introducir desequilibrios normativos significativos al contrato, han sido adecuadamente informadas al adherente. Se propone que la apreciación de abusividad se mantenga en los límites abstractos contemplados en la mentada 16 letra g), fundando el control de sorpresividad en otras reglas de la ley No 19.496 y del Código Civil.
\end{abstract}

Palabras clave: Control de contenido, control de sorpresividad, apreciación abstracta, circunstancias concurrentes.

ABSTRACT: In the light of the models found in German law and in the Directive 93/13 / $\mathrm{EEC}$, is analysed the unfairness assessment model that is established in article 16 letter $\mathrm{g}$ ) of Law No. 19,496. It is explained how part of our doctrine and jurisprudence approach the content control to the control of surprising terms. It is argued that this approach entails the risk of distorting the content control, justifying the validity of clauses that, despite introducing significant regulatory imbalances to the contract, have been adequately informed to the adherent. It is proposed that the unfairness assessment of abuse should be maintained within the abstract limits of the referred letter g), based on the surprising control in other rules of Law No. 19.496 and the Civil Code.

Keywords: content control, control of surprising terms, abstract appreciation, concurrent circumstances.

\footnotetext{
Magíster en Derecho mención en Derecho Privado, Universidad de Chile. Profesor instructor del Departamento de Derecho Privado, Universidad de Chile. Dirección postal: Pío Nono 1, Providencia. Dirección electrónica: scampos@derecho.uchile.cl. Número Orcid: 0000-0002-3236-8630
} 


\section{INTRODUCCIÓN}

Como es sabido, la Ley No 19.955, de 14 de julio de 2004, modificó el párrafo $4^{\circ}$ del título II de la ley No 19.496 -ley que establece normas sobre protección de los derechos de los consumidores, de 7 de marzo de 1997 (en adelante LPDC)-, agregando, en lo que nos interesa, una letra g) al artículo 16, según la cual no producen efecto alguno las cláusulas o estipulaciones no negociadas individualmente que "en contra de las exigencias de la buena fe, atendiendo para estos efectos a parámetros objetivos, causen en perjuicio del consumidor, un desequilibrio importante en los derechos y obligaciones que para las partes se deriven del contrato" ${ }^{1}$. Se perfecciona así el control de contenido, el cual antes de la modificación se acotaba a los casos en que alguna cláusula se subsumiera en las letras a) a f) del artículo $16^{2}$. El control tiene por objetivo resguardar cierta medida de equilibrio en el contenido normativo del contrato $^{3}$ y, por mor del artículo noveno No 2 de la Ley No 20.416 -de 3 de febrero de 2010-, resulta aplicable a todos los contratos cuyos adherentes tengan la calidad de consumidores o micro o pequeñas empresas 4 .

Según la mentada letra g), para la apreciación del desequilibrio importante "se atenderá a la finalidad del contrato y a las disposiciones especiales o generales que lo rigen". No obstante, doctrina autorizada postula que el juez está habilitado para considerar, entre otras circunstancias concurrentes a la celebración del contrato, la fuerza de las posiciones negociales, el hecho de que el adherente haya sido inducido por el proveedor a celebrar el contrato o que los bienes y servicios hayan sido provistos al adherente a pedido suyo, la naturaleza de los bienes y servicios y las demás cláusulas del contrato o de otros contratos entre las partes 5 . Esta aproximación, que sigue de cerca el modelo establecido en la Directiva 93/13/CEE, de 5 de abril de 1993, sobre las cláusulas abusivas en los contratos celebrados con consumidores (en adelante Directiva 93/13/CEE), ha encontrado cierto reflejo en la jurisprudencia, presentándose como una alternativa digna de consideración.

Con todo, si bien la consideración de las mentadas circunstancias puede reforzar la tutela del adherente, también entraña el riesgo de que el control sea confundido con uno de sorpresividad, trasladando el foco desde el resguardo de cierta medida de equilibrio normativo hacia la comprobación de que la información entregada al adherente de forma previa o simultánea a la celebración del contrato ha tornado razonablemente previsible la cláusula sometida a examen. Este último extremo, además de desvirtuar el control establecido por el legislador, merma la protección de los intereses del adherente, máxime si se con-

\footnotetext{
${ }^{1}$ La disposición no es novedosa en derecho comparado, siendo evidente su inspiración en el artículo 3.1 de la Directiva 93/13/CEE, de 5 de abril de 1993, sobre las cláusulas abusivas en los contratos celebrados con consumidores (Momberg y Pizarro (2013) p. 342).

2 Para un análisis de las letras a) a f), TAPIA y Valdivia (1999) pp. 92-126.

3 Incluso antes de que entrara en vigor la ley No 19.955, Tapia y Valdivia referían la conservación de un equilibrio razonable como la finalidad del control de contenido. TAPIA y VALDIVIA (1999) pp. 40-44.

4 Sobre el impacto de la Ley No 20.416 en el ámbito de aplicación de la LPDC, Momberg (2012) pp. 377-391.

5 De la Maza (2004) pp. 23 y 24, Barcia (2016) p. 109.
} 
sidera que, según autorizados estudios de economía conductual, los consumidores y micros y pequeñas empresas tienen una racionalidad limitada ${ }^{6}$.

Así las cosas, en este trabajo se expondrá la evolución que ha experimentado el control de contenido en la doctrina y jurisprudencia nacional, presentando las razones por las que debe preferirse una apreciación abstracta de abusividad o, a lo sumo, una apreciación concreta que, no obstante considerar las circunstancias concurrentes, no implique en ningún caso la justificación de cláusulas que introduzcan desequilibrios normativos importantes al contrato. Para estos efectos, haremos una revisión sintética del desarrollo y regulación de la materia en el derecho alemán y en la Directiva 93/13/CEE, analizando luego, a luz de las conclusiones obtenidas, la cuestión en el derecho nacional.

\section{EL MODELO DE APRECIACIÓN DE ABUSIVIDAD EN LA TRADICIÓN ALEMANA}

Con base en desarrollos jurisprudenciales de la primera mitad del siglo XX, la Gesetz zur Regelung des Rechts der Allgemeinen Geschäftsbedingungen, de 9 de diciembre de 1976, en adelante AGBG, estableció dos controles de diversa naturaleza y alcance: por un lado, el de incorporación, orientado a resguardar la cognoscibilidad, comprensibilidad y razonable previsibilidad de las condiciones generales; por el otro, el de contenido, orientado a resguardar cierta medida de equilibrio en su contenido normativo.

En cuanto al control de incorporación, el $\$ 2$ dispuso que las condiciones generales, para formar parte de un contrato, debían cumplir dos cargas: en primer lugar, que quien se sirviera de ellas, en el momento de la celebración del contrato, hubiese informado expresamente al adherente de su existencia o, siendo ello posible con una dificultad desproporcionada, al menos hubiese publicado de forma visible un anuncio referido a ellas en el lugar de celebración; en segundo lugar, que quien se sirviera de ellas hubiese otorgado al adherente una oportunidad para tomar nota de su existencia y aceptar su incorporación al contrato ${ }^{7}$. Por su parte, el $\$ 3$, positivizando el control de sorpresividad que el Tribunal Supremo federal venía practicando desde la década de los sesenta, dispuso que no forman parte de un contrato las condiciones que, con base en la apariencia externa del contrato y las circunstancias concurrentes a su celebración, no sean razonablemente previsibles ${ }^{8}$. Finalmente, el $\$ 4$ consagró la regla de la prevalencia, según la cual las cláusulas negociadas -y también las

\footnotetext{
6 Simon (1955) pp. 99-118, Sunstein y Thaler (2003) pp. 1159-1202 y Loewenstein y O’Donoghue (2006) pp. 183-206.

7 Según Kötz y Schlosser, la carga de proporcionar al adherente la posibilidad de conocer el contenido de las condiciones generales presupone que estas hayan sido redactadas de forma clara y comprensible (GonZÁLEZ (2000a) p. 141, nota al pie No 5). Empero, a partir de la década de los ochenta, la claridad y comprensibilidad comenzó a ser examinada por la jurisprudencia alemana con ocasión del control de contenido, dando lugar a la doctrina de la abusividad por falta de transparencia (GonZÁlez (2000b) p. 248, Pertíñez (2004) pp. 113-119, Cámara (2006) pp. 27 y 28. Respecto a los contratos entre empresarios, Albiez (2009) pp. 46-49).

8 Sobre el control de sorpresividad, Alfaro (1991) pp. 241-275, Pagador (1999) pp. 490-515, Pagador (2011) pp. 1363-1370, Pertíñz (2004) pp. 193-215.
} 
impuestas específicamente para un contrato particular- desplazan a las condiciones generales incompatibles, desincorporándolas del contenido del contrato?.

En lo que respecta al control de contenido, la AGBG consagró una lista gris $(\$ 10)$ y una negra $(\$ 11)$ de condiciones generales abusivas ${ }^{10}$. Por su parte, recogiendo una línea jurisprudencial cuyas bases se remontan a $1906^{11}$, el $\$ 9.1$ estableció que "las cláusulas en condiciones generales de contratación son ineficaces si, en contra de las exigencias de la buena fe, perjudican injustificadamente a la contraparte contractual del predisponente". En este orden, reconociendo los parámetros que antes perfilara el Tribunal Supremo Federal para la apreciación de abusividad, el $\$ 9.2$ dispuso que "en la duda, se presume un perjuicio injustificado: 1. cuando la cláusula no sea compatible con los principios fundamentales de la legislación de que se aparta; 2. cuando limite los derechos y deberes esenciales derivados de la naturaleza del contrato poniendo en peligro la realización de su propia finalidad" ${ }^{12}$.

A la luz del $\mathbb{S} 9.1$, los elementos que configuran la abusividad de una cláusula son la contravención a las exigencias de la buena fe y el perjuicio injustificado al adherente.

La función atribuida a la buena fe se traduce en el control de cómo y en qué medida la estructura jurídica predispuesta satisface los intereses del adherente; tal control, conocido en la doctrina alemana como Inhaltskontrolle, es eminentemente abstracto y se realiza en torno a los intereses típicos del adherente, que no son sino aquellos tutelados mediante las reglas del derecho dispositivo ${ }^{13}$. En esta línea, la buena fe sirve de fundamento del control, permitiendo sustentar que una cláusula predispuesta que perjudica injustificadamente al adherente no produce efectos. De ahí entonces que el elemento determinante para la apreciación de abusividad sea el perjuicio injustificado ${ }^{14}$.

El perjuicio injustificado se configura cuando la cláusula no sea compatible con los principios fundamentales de la legislación de que se aparta o cuando limita los derechos y deberes esenciales derivados de la naturaleza del contrato poniendo en peligro la realización de su propia finalidad. Estas dos hipótesis de abusividad pueden reconducirse a una misma idea: que la desviación del derecho dispositivo sea de tal medida que ponga en riesgo la satisfacción de las expectativas típicas del adherente. A este respecto, el derecho dispositivo no se refiere únicamente a la regulación supletoria existente para el contrato que en concreto sea celebrado, sino también a aquellas reglas supletorias contempladas en la regulación general de los contratos ${ }^{15}$.

Distinto es el caso del control de sorpresividad, el que, si bien se realiza a la luz del estándar de un adherente de diligencia ordinaria, atiende a las circunstancias concurrentes a la celebración del contrato, siendo un control eminentemente concreto. En principio, una

\footnotetext{
9 Alfaro (1991) pp. 245 y 253, Patti y Patti (1993) p. 471, Díaz (2000) p. 202.

10 Ebers (2016) p. 145.

11 Zimmermann (2008) pp. 201 y 202.

12 Zimmermann (2008) p. 202.

13 Albanese (2013) p. 702.

14 Albanese (2013) p. 701.

15 Extrapolando el punto, Carrasco Perera ha sustentado que el marco de referencia no solo está compuesto por el derecho dispositivo, sino también por la eventual existencia de costumbres, usos mercantiles o, derechamente, consensos sociales racionales y lógicos (CARRASCO (2017) pp. 779-782).
} 
cláusula es sorprendente cuando, de acuerdo con las circunstancias y la apariencia externa del contrato, el efecto que provoca es tan inusual que no resulta razonable para el adherente prever su existencia. Para superar este control quien se sirve de condiciones generales debe satisfacer una carga particular, a saber, informar, de manera previa o simultánea a la celebración del contrato, el contenido, sentido y alcance de las mentadas condiciones, de modo que su aplicación sea razonablemente previsible para un adherente de diligencia ordinaria ${ }^{16}$.

Ante el éxito del modelo instaurado, el legislador alemán, una vez que decidió la integración del derecho de las condiciones generales de contratación en el BGB, incorporó a este último el contenido íntegro de la AGBG mediante reforma de enero de $2002^{17}$. En la materia que nos interesa, los parágrafos 2, 3, 4, 9, 10 y 11 de la AGBG pasaron a ser los parágrafos 305(2), 305c, 305b, 307, 308 y 309 del BGB. Además, el legislador alemán aprovechó la ocasión para positivizar, en el mismo $\$ 307$, la doctrina jurisprudencial relativa a la posibilidad de que la abusividad de una cláusula provenga de la falta de una redacción clara y comprensible ${ }^{18}$.

\section{EL MODELO DE APRECIACIÓN DE ABUSIVIDAD EN LA DIRECTIVA 93/13/CEE}

A diferencia de la AGBG, la Directiva No 93/13/CEE, de 5 de abril de 1993, no establece un control de incorporación, pues los artículos 4.2 y 5 de la Directiva no vinculan la falta de claridad y comprensibilidad de las cláusulas a su no incorporación, sino a la posibilidad de que sean apreciadas como abusivas ${ }^{19}$. Por lo demás, el Tribunal de Justicia de la Unión Europea (en adelante TJUE), en el marco del desarrollo de su doctrina acerca de la incardinación del control de transparencia en el de contenido, ha sostenido expresamente que el deber de transparencia establecido en el artículo 5 tiene el mismo alcance que el establecido en el artículo $4.2^{20}$.

En cuanto al control de contenido, el artículo 3.1 de la Directiva establece que "las cláusulas contractuales que no se hayan negociado individualmente se considerarán abusivas si, pese a las exigencias de la buena fe, causan en detrimento del consumidor un desequilibrio importante entre los derechos y obligaciones de las partes que se derivan del contrato". En una línea cercana a la alemana, la norma contempla dos elementos para configurar la abusividad: la contravención a la buena fe y el desequilibrio importante entre los derechos y obligaciones. Respecto de la contravención de las exigencias de la buena fe, el

\footnotetext{
16 Alfaro (1991) pp. 241-275, Pagador (2011) pp. 1363-1370 Pertíñez (2004) pp. 193-215.

17 Albiez (2002) pp. 1147-1151.

$18 \mathrm{El}$ actual $\$ 307$ dispone que "también puede resultar un perjuicio injustificado del hecho que la cláusula no sea clara y comprensible”.

19 Carballo (2010) p. 11, Blandino (2012) p. 589. Con relación a la extensión del control de contenido a las cláusulas relativas a elementos esenciales del contrato cuando estas no hayan sido redactadas de forma clara y comprensible, Pertíñez (2004) pp. 112 y 113, Pertíñez (2013) p. 9, Pertíñez (2017) 98-101, Farneti (2009) pp. 282-294, CÁmara (2006) p. 17. Entre nosotros, refiriéndose al control de transparencia, De la MAZA y MOMBerg (2018) pp. 87-98.

20 KASLER Y KASLERNÉ RABAi CONTRA OTP JELZALOGBANK ZRT (2014), apartado 69; BogdAN MATEI Y IOANA OfELIA MATEI CONTRA SC VOLKSBANK ROMÂNIA SA (2015), apartado 73.
} 
TJUE, en sentencia de 14 de marzo de 2013, ha entendido que "en lo que se refiere a la cuestión de en qué circunstancias se causa ese desequilibrio "pese a las exigencias de la buena fe» (...) el juez nacional debe comprobar a tal efecto si el profesional podía estimar razonablemente que, tratando de manera leal y equitativa con el consumidor, este aceptaría una cláusula de ese tipo en el marco de una negociación individual" 21 . Por su parte, en lo que se refiere al desequilibrio importante, el TJUE estima que "para determinar si una cláusula causa en detrimento del consumidor un «desequilibrio importante» entre los derechos y las obligaciones de las partes que se derivan del contrato, deben tenerse en cuenta, en particular, las normas aplicables en Derecho nacional cuando no exista un acuerdo de las partes en ese sentido. Mediante un análisis comparativo de ese tipo, el juez nacional podrá valorar si -y, en su caso, en qué medida- el contrato deja al consumidor en una situación jurídica menos favorable que la prevista por el Derecho nacional vigente" ${ }^{22}$. Con todo, en el marco de la Directiva también se plantea la cuestión de si acaso la buena fe realmente desempeña un rol importante en la apreciación de la abusividad o si simplemente constituye su fundamento y criterio de justificación ${ }^{23}$.

Como sea, alejándose del modelo alemán, la Directiva establece en su artículo 4.1 tres parámetros que orientan la apreciación de abusividad: la naturaleza de los bienes o servicios que sean objeto del contrato, todas las circunstancias que concurran en el momento de su celebración, y todas las demás cláusulas del contrato o de otro contrato del que dependa. Sin perjuicio de los matices pertinentes -destacando, entre otros, la prescindencia de las circunstancias concurrentes en el marco del control general ${ }^{24}$-, los mentados parámetros, y en particular la consideración de las circunstancias concurrentes, sirven para concretizar la tutela al adherente, sustentándose en la premisa de que los contratos por adhesión, aunque se alejen del modelo clásico de contratación, siguen teniendo naturaleza contractual, debiendo ser consideradas las particularidades de cada concreta relación ${ }^{25}$. En esta línea, y según explicita el considerando decimosexto de la Directiva, entre otras circunstancias, deben considerarse la fuerza de las respectivas posiciones negociadoras de las partes, si acaso se ha inducido de algún modo al consumidor a dar su acuerdo a la cláusula, o si los bienes se han vendido o los servicios se han prestado a petición especial del consumidor.

En este marco, y habida cuenta de la inexistencia de un control de incorporación en la Directiva, doctrina autorizada sostiene que la consideración de las circunstancias concurrentes implica incardinar el control de sorpresividad en el de contenido, de forma tal de predicar la abusividad de las cláusulas que, por la apariencia externa del contrato y las de-

\footnotetext{
21 Mohamed Aziz contra CaiXa d'Estalvis de Catalunya, Tarragona i Manresa (CatalunyaCaixa) (2013), apartado 69.

22 Mohamed Aziz contra CaiXa d'Estalvis de Catalunya, Tarragona i Manresa (Catalunyacaixa) (2013), apartado 68.

23 González (2015) p. 1113. Algunos Estados, a la hora de transponer el artículo 3.1 de la Directiva, han consagrado cláusulas generales que, requiriendo expresamente el desequilibrio significativo, omiten toda remisión a la buena fe. Así ocurre, por ejemplo, en Bélgica, Dinamarca, Estonia y Grecia (Ebers (2016) p. 153). Así ocurre también en Francia. El artículo L 132-1 del Code de la Consommation dispone: "sont abusives les clauses qui ont pour objet ou pour effet de créer, au détriment du non-professionnel ou du consommateur, un déséquilibre significatif entre les droits et obligations des parties au contrat".

24 Campos (2019) pp. 43 y 44.

25 Ballesteros (1999) p. 210.
} 
más circunstancias concurrentes, no sean previsibles para un adherente de diligencia ordinaria ${ }^{26}$. En este orden, una circunstancia concurrente que cobra relevancia para la apreciación de abusividad es la deficiencia de la información entregada respecto a las cláusulas que desempeñen una función significativa en la determinación de la carga económica y jurídica que implica el contrato para el consumidor ${ }^{27}$.

Ahora bien, la exigencia de considerar las circunstancias concurrentes en el marco del control de contenido entraña una cuestión de suma relevancia, a saber, si acaso la apreciación de abusividad puede evitarse por el hecho de que quien se sirva de cláusulas no negociadas haya informado adecuadamente respecto al contenido de estas. Una respuesta afirmativa implicaría que la consideración de la información entregada y el análisis de su adecuación trasladarían el enfoque del control desde el resguardo de cierta medida de equilibrio normativo hacia el aseguramiento de una adecuada formación del consentimiento. En este orden, ya no habría una mera incardinación del control de sorpresividad en el de contenido, sino una completa identidad.

Evidentemente, incluso en la poco realista hipótesis de que el adherente entienda a cabalidad los alcances económicos y jurídicos del contenido predispuesto ${ }^{28}$, identificando groseros y significativos desequilibrios en su perjuicio, es posible que, por la urgencia de satisfacer necesidades personales o familiares, celebre igualmente el contrato. Por lo demás, dado que la predisposición de cláusulas abusivas constituye una falla de mercado, es probable que todos los competidores que participan en el mismo mercado ofrezcan el mismo contenido abusivo ${ }^{29}$.

Justificar el contenido de una cláusula en razón de la información entregada entraña el monumental riesgo de legitimar una práctica que el derecho busca prevenir, esto es, la utilización de cláusulas no negociadas que pongan en riesgo la satisfacción de las expectativas típicas del adherente ${ }^{30}$. Por ello, la consideración de las circunstancias concurrentes en el marco del control de contenido no debe impedir la apreciación de abusividad a la luz de parámetros abstractos, sino que debe servir como un complemento para apreciar la abusividad -rectus, sorpresividad- de aquellas cláusulas que, sin desviarse ostensiblemente del derecho dispositivo, provocan una defraudación de las expectativas que el adherente se ha forjado en función de las concretas y singulares circunstancias que han concurrido a la celebración del contrato ${ }^{31}$. Doctrina autorizada está conteste en que la entrega de la mejor y más completa información no justifica la eficacia de una cláusula que no haya superado una apreciación abstracta de abusividad, pues el control de contenido no se dirige a la comprobación de un consentimiento real o presuntivo por parte del adherente, sino a resguardar que exista cierta medida de equilibrio en el contenido normativo del contrato ${ }^{32}$.

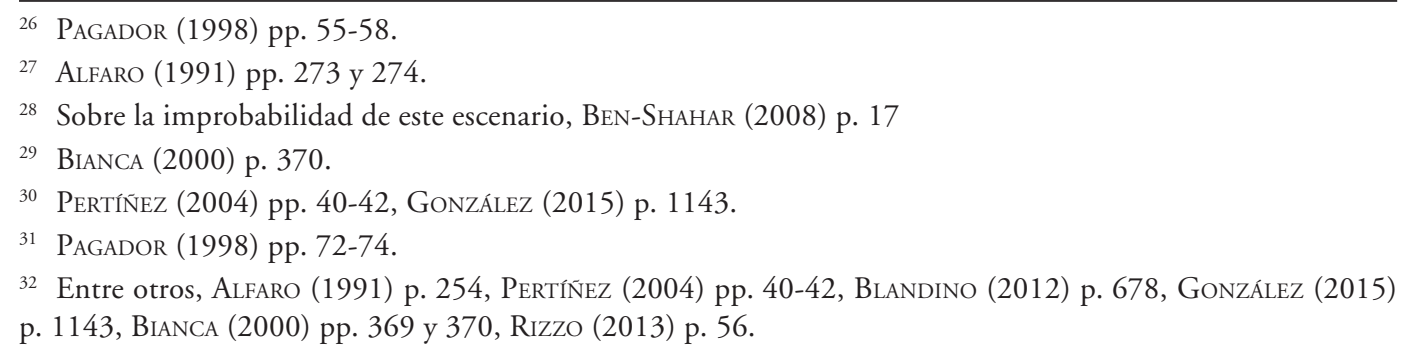


Antes de finalizar esta sección, hay que añadir que el modelo de la Directiva no solo predomina en los ordenamientos europeos -en que el deber de armonización mínima exigido por el artículo 8 ciertamente ha surtido efecto ${ }^{33}$-, sino también en los instrumentos de derecho uniforme y de armonización. Así ocurre, por lo demás, en los artículos II.-9:407 del DCFR, 6:301 de los ACQP y 4:110 de los PECL.

\section{EL MODELO DE APRECIACIÓN DE ABUSIVIDAD EN LA LPDC}

En nuestro sistema, la LPDC establece un control de incorporación -diseñado por la letra f) ${ }^{34}$ del artículo 16 y fundamentalmente por los artículos 17 y $12 \mathrm{~A}^{35}$ - y un control de contenido -compuesto por las diversas letras del artículo 16, salvo la f)-.

En lo que atañe al control de incorporación, el artículo 17 establece que las cláusulas que no estén redactadas de modo claramente legible, con un tamaño de letra no inferior a 2,5 milímetros y en idioma castellano -salvo aquellas palabras de otra lengua que el uso haya incorporado al léxico-, "no producirán efecto alguno respecto del consumidor". Adicionalmente, el inciso segundo del mentado artículo 17 consagra la regla de la prevalencia, disponiendo que "en los contratos impresos en formularios prevalecerán las cláusulas que se agreguen por sobre las del formulario cuando sean incompatibles entre sí”. Por su parte, respecto de la contratación a distancia, el artículo 12 A consagra una carga de cognoscibilidad, consistente en resguardar la accesibilidad de las condiciones generales del contrato y la posibilidad de almacenarlas o imprimirlas.

Sin perjuicio de que la regla de la prevalencia pueda ser concebida como una concreción del control de sorpresividad ${ }^{36}$, no se consagra en nuestro sistema un control general de esta última clase.

En cuanto al control de contenido, este se estructura sobre la base de una lista negra -letras a) a e) del artículo $16^{37}$ - y una cláusula abierta -letra g) del artículo 16-. Según la letra g), una cláusula es abusiva cuando en contra de las exigencias de la buena fe, atendiendo para estos efectos a parámetros objetivos, cause, en perjuicio del adherente, un desequilibrio importante en los derechos y obligaciones que para las partes se deriven del contrato. Tal como ocurre a propósito del artículo 3.1 de la Directiva, si bien la letra g) refiere dos elementos para que se configure la abusividad -la contravención a las exigencias de la buena fe y el desequilibrio importante en los derechos y obligaciones-, doctrina au-

\footnotetext{
33 Véase, por ejemplo, artículos L 212-1 del Code de la Consommation, 34.1 del Codice del Consumo, y 82.3 del TRLGDCU. En el mismo BGB, el actual $\int 310$ apartado 3 número 3 establece que, en el caso de contratos celebrados entre empresarios y consumidores, la apreciación del perjuicio injustificado ha de tener en cuenta las circunstancias concurrentes al momento de la celebración del contrato.

34 Tapia y Valdivia (1999) pp. 75-77.

35 De la Maza (2004) p. 15, Morales (2018) pp. 85-87. Para un examen más detallado, Tapia y Valdivia (1999) pp. 59-78, Pizarro y Pérez (2013) pp. 359-363, Contardo (2014) pp. 113-127, Barrientos (2018) pp. 1001-1018.

36 Alfaro (1991) pp. 245 y 253, Patti y Patti (1993) p. 471, Pagador (1998) pp. 103 y 104, Díaz (2000)

p. 202.

37 Tapia y Valdivia (1999) pp. 90-91.
} 
torizada sostiene que basta con la constatación de este último ${ }^{38}$. En rigor, las exigencias de la buena fe se concretan en la exigencia de que el profesional se sirva de un contenido predispuesto equilibrado, que no entorpezca la satisfacción de las expectativas que alberga el adherente según la naturaleza del contrato, de modo que el desequilibrio importante revela por sí mismo una contravención a la buena fe ${ }^{39}$. Esta aproximación ha encontrado acogida implícita o explícita en la jurisprudencia de nuestros tribunales ${ }^{40}$, destacando en el último tiempo sentencias de 9 de abril de 2018, 15 de abril de 2019 y 27 de diciembre de 2019, todas de la Corte Suprema, que, sin hacer referencia a la buena fe, afirman "que el carácter abusivo de las estipulaciones contractuales está determinado por el desequilibrio notable e injustificado en las prestaciones que la estipulación impone, en perjuicio del adherente consumidor y en beneficio del predisponente proveedor" ${ }^{41}$.

En cuanto al modelo de apreciación de abusividad, la letra g) dispone que "se atenderá a la finalidad del contrato y a las disposiciones especiales o generales que lo rigen”. Se consagra, en principio, el modelo de apreciación abstracta, pues la remisión a la finalidad del contrato y a las disposiciones especiales o generales que lo rigen puede entenderse realizada a las expectativas típicas que puede albergar el adherente en función de la naturaleza del contrato y a las reglas de derecho dispositivo que lo regulan. En este sentido, el control resguarda la finalidad típica que subyace al contrato, esto es, la función socioeconómica que sirve como su causa ${ }^{42}$, plasmada en la regulación contemplada en el derecho dispositivo ${ }^{43}$.

Con todo, como veremos a continuación, existe doctrina autorizada y también jurisprudencia que ponen en cuestión este modelo.

\section{El ACERCAMIENTO DEL CONTROL DE CONTENIDO AL CONTROL DE SORPRESIVIDAD EN LA DOCTRINA}

Uno de los autores que ha acercado el control de contenido al de sorpresividad es Barcia. Según el autor, "no cualquier modificación o exclusión de un elemento de la naturaleza o un elemento incorporado al contrato puede ser calificado como atentatorio contra la buena fe. El juez para poder llegar a esta conclusión debe integrar estos criterios, es

\footnotetext{
38 De la Maza Gazmuri sostiene que la constatación de un desequilibrio importante podría servir de base de una presunción de mala fe (De La Maza (2004) pp. 18 y 19). Por su parte, Momberg Uribe y Pizarro Wilson sugieren que todo desequilibrio importante implica en sí una contravención a la buena fe o es al menos indiciario de ella (Momberg y Pizarro (2013) pp. 343-347). En el mismo sentido, Morales y Veloso (2019) p. 154.

39 GonZÁLEZ (2015) p. 1113.

40 HUBNER Y JUAREZ CON UNIVERSIDAD MAYOR (2008), considerando cuarto, apartado cuatro; PARRA CON UNIVERSIDAD ANDRÉS BELLO (2008), considerando sexto; RAVINET CON UNIVERSIDAD ANDRÉS BELLO (2012), considerando segundo; SERNAC CON CENCOSUD ADMINISTRADORA DE TARJETAS S.A. (2013), considerandos octavo, noveno y décimo; SERNAC CON CRÉDITOS ORGANIZACIÓN Y FINANZAS S.A. (2014), considerando vigesimoséptimo; SERNAC CON TICKET FACIL S.A. (2018), sentencia de nulidad, considerandos décimo y undécimo. Para una revisión de estas sentencias, Momberg y Pizarro (2013) pp. 348 y 349, Campos (2019) pp. 242-244.

41 SERNAC CON TICKETMASTER CHILE S.A. (2018), sentencia de nulidad, considerando duodécimo; SERNAC CON CORPORACIÓN EDUCACIONAL UNIVERSIDAD DEL MAR (2019), sentencia de nulidad, considerando séptimo; SERNAC CON Constructora SANTA BeAtriz S.A. (2019), sentencia de nulidad, considerando séptimo.

42 Carvajal (2011) pp. 441-448.

43 Lorenzini y Polit (2013) pp. 468-472.
} 
decir, sospechará de estas cláusulas, y las tendrá por abusivas solo en la medida que el predisponente no pueda probar que informó adecuadamente al consumidor de ellas, para lo cual no le bastará el mero contrato, y sobre todo, si ellas no tienen como contrapartida un beneficio" "44. Los criterios a que se refiere el autor son justamente los parámetros de la letra g) del artículo $16^{45}$, de modo que, bajo su esquema de razonamiento, la entrega oportuna de información veraz y suficiente respecto de las cláusulas no negociadas podría impedir la apreciación de abusividad o cuanto menos jugar un rol relevante al respecto.

Una postura más matizada es la de De la Maza ${ }^{46}$. Según este autor, debe presumirse la validez de las cláusulas que, sin subsumirse en la lista negra diseñada en las letras a) a f) del artículo 16 de la LPDC, tienen un contenido que resulta legible y comprensible para una persona promedio dentro del público al que se dirige la oferta; en estos casos cobra aplicación la carga de informarse que recae sobre los adherentes, de modo que la adhesión -que implica aceptación- excluye, en principio, la abusividad ${ }^{47}$. Por el contrario, si la cláusula, sin llegar al extremo de subsumirse en la lista negra, y pese a ser informada por el profesional, no resulta legible o comprensible para un adherente medio -sea por la utilización de vocablos técnicos, por la remisión a otras cláusulas o reglamentos, o por regular extremos de alcance complejo-, la carga de informarse no cobra aplicación -por desproporcionada-, debiendo apreciarse su validez o eventual abusividad a la luz de las expectativas razonables que pueda albergar dicho adherente ${ }^{48}$. En este orden, el autor propone que el control diseñado por la letra g) del artículo 16 sea realizado según las expectativas razonables que un adherente medio, sobre la base del tipo contractual y de la publicidad y los tratos preliminares, puede albergar en la ejecución del contrato ${ }^{49}$. En consecuencia, a diferencia de lo que ocurre en los contratos de contenido legible y comprensible -en que el control de las cláusulas se acercaría sustantivamente a un mero control de sorpresividad-, tratándose de contratos por adhesión de contenido complejo, el control de contenido tutelaría tanto las expectativas resguardadas por el derecho dispositivo como aquellas que un adherente de diligencia ordinaria podría forjarse en función de las circunstancias concurrentes a la celebración.

En una línea afín, Pinochet, otro jurista de prestigio, ha sostenido recientemente que "el contrato de adhesión no alcanza fuerza obligatoria por el solo hecho de su suscripción formal, sino que lo hará a condición de que sea el producto de una manifestación de voluntad del adherente verdaderamente libre e informada, lo que trae como consecuencia que

\footnotetext{
44 BARCIA (2016) pp. 108 y 109.

45 BARCIA (2016) p. 108.

46 De la Maza tempranamente afirmó que el juez, si bien no puede desatender la finalidad del contrato y las disposiciones que lo rigen, está habilitado para considerar, entre otras circunstancias, la fuerza de las posiciones negociales, el hecho de que el adherente haya sido inducido por el proveedor a celebrar el contrato o que los bienes y servicios hayan sido provistos al adherente a pedido suyo, la naturaleza de los bienes y servicios y las demás cláusulas del contrato o de otros contratos entre las partes. DE LA MAZA (2004) pp. 23 y 24 . En el mismo sentido, BARCIA (2016) p. 109.

47 De la MaZa (2014) pp. 339 y 340.

48 De la Maza (2014) p. 340.

49 De la Maza (2014) pp. 343-349.
} 
en el caso de que las condiciones del contrato no coincidan con lo que él creyó contratar, las cláusulas escritas deberán ser desplazadas por sus legítimas expectativas, bajo condición de que estas sean razonables" ${ }^{50}$. Según el autor, que también acerca el control de contenido al de sorpresividad ${ }^{51}$, la noción de expectativas razonables o legítimas expectativas se determina sobre la base de aquello que un adherente de diligencia ordinaria podría esperar de la ejecución del contrato ${ }^{52}$. Pese a ello, en la misma línea que De la $\mathrm{Maza}^{53}$, Pinochet refiere la importancia que ostentan las cosas de la naturaleza (ex artículo 1444 del Código Civil) como una concreción de lo que resulta razonable $e^{54}$, refrendando así que las reglas de derecho dispositivo reflejan una medida de justicia conmutativa de la que el predisponente difícilmente puede distanciarse sin defraudar las expectativas del adherente.

\section{El CONTROL DE CONTENIDO EN LA JURISPRUDENCIA}

Dado que la letra g) del artículo 16 fue incorporada a la LPDC por la Ley No 19.955 , de 14 de julio de 2004, el desarrollo jurisprudencial de la temática es reciente.

En sentencia de 21 de septiembre de 2007, la Corte de Apelaciones de Santiago, a propósito de los parámetros de apreciación establecidos por el legislador, afirma que "para determinar la finalidad del contrato, se ha entendido que se deben examinar las expectativas que el consumidor, razonablemente, podría haberse hecho respecto del contrato, lo que implica que uno de los principales elementos para limitar el contenido abusivo de los contratos por adhesión, se encuentra en la noción de defraudación de expectativas del adherente" 55 . Según viéramos, las expectativas a tutelar podrían determinarse sobre la base de la naturaleza del contrato y los intereses que al respecto tutela el derecho dispositivo; sobre la base de la publicidad, la información precontractual y las demás circunstancias concurrentes; o sobre ambas bases. En el caso particular, a propósito de un contrato de tiempo compartido, la Corte aprecia la abusividad de dos cláusulas por no estar destacadas entre las cláusulas principales del contrato (se encontraban contempladas en un reglamento al que el contrato se remitía) y no haber sido adecuadamente informadas al adherente, defraudando así las expectativas que este albergaba en la ejecución del contrato ${ }^{56}$.

\footnotetext{
50 Pinochet (2019) pp. 498 y 499.

51 En palabras de Pinochet, "La arbitrariedad de la posición dominante en el proceso de contratación se produce fundamentalmente a través de las denominadas cláusulas abusivas o las cláusulas sorprendentes, esto es, cláusulas que siendo aparentemente válidas contradicen, sin embargo, los presupuestos elementales del Derecho de la contratación" (PinOChet (2019) p. 508).

52 Pinochet (2019) p. 502.

53 De la Maza (2014) pp. 346 y 347.

54 PinOChet (2019) p. 511.

55 Camus con Comercializadora Alto Manatagua S.A. (2007), considerando primero.

56 Una cláusula imponía el pago de una cuota de membresía, además del precio convenido en el contrato, para el caso en que el adherente no utilizara el complejo habitacional y deseara mantener su calidad de socio; la otra establecía que el no pago de tres cuotas de membresía producía la extinción de los beneficios del programa vacacional contratado. La Corte también aprecia la abusividad de una cláusula que imponía el pago de una cuota por cada semana de utilización del complejo por concepto mantención del establecimiento, servicio de mucama, ropa blanca, uso de instalaciones deportivas, entre otras (CAMUS CON COMERCIALIZADORA ALTO MANATAGUA S.A. (2007), considerandos undécimo, duodécimo y decimotercero).
} 
Posteriormente, en sentencias de 3 de junio de 2014 y 13 de enero de 2015, la misma Corte señala que, para efectos de constatar el desequilibrio importante al que se refiere la letra g), "lo relevante es la afectación a los derechos y obligaciones de los consumidores, ya sea que se altere el derecho dispositivo en contra del consumidor o, desde la perspectiva de este, se fractura el propósito práctico del contrato" ${ }^{27}$. A la luz de la doctrina comparada expuesta, este considerando podría ser entendido en el sentido de que la abusividad puede derivar de un distanciamiento del derecho dispositivo que pone en riesgo las expectativas típicas del adherente o de una defraudación de las expectativas que este se ha forjado sobre la base de la información, la publicidad y las demás circunstancias concurrentes a la celebración.

En otro pronunciamiento, de 7 de julio de 2016, la Corte Suprema aprecia la abusividad de una condición general que, reglando el procedimiento para la adquisición de entradas a un espectáculo, faculta a Ticketmaster para revelar a terceros la información proporcionada por los usuarios, recolectar información derivada de sus gustos, preferencias y utilización que hagan de los servicios, y utilizar la información recolectada con fines comerciales $^{58}$. Al respecto, la Corte sostiene que "resulta contraria a la buena fe, y en consecuencia abusiva, la obtención del consentimiento del titular de los datos mediante una condición general de contratación incluida en una transacción cuyo objeto principal es la entrada a un espectáculo. En el contexto de semejante transacción comercial, tal renuncia a la privacidad de los datos personales solo es válida si es otorgada en forma explícita y específica" ${ }^{59}$. La apreciación de abusividad se basa en la imprevisibilidad de una autorización como esta en un contrato de este tipo. Se trata, en consecuencia, de un control de sorpresividad, que puede ser superado en caso de que el adherente sea informado adecuadamente acerca de la existencia de la cláusula y su sentido y alcance, aceptándola explícita y separadamente. Aunque no se explicita, la Corte parece entender que el contenido de la cláusula no es en sí mismo desequilibrado.

Dado que ninguno de los fallos referidos llega al extremo de sostener que una información adecuada respecto al contenido de una cláusula sea siempre suficiente para excluir su abusividad, la jurisprudencia hasta ahora comentada podría enmarcarse en la doctrina que incardina el control de sorpresividad en el de contenido sin llegar a identificarlos y con el preciso fin de ampliar la tutela al adherente. En este sentido debiese interpretarse sentencia de nulidad de 7 de marzo de 2018, en que la Corte Suprema, luego de precisar que el control vela por el equilibrio contractual y referir los parámetros de apreciación contemplados en la letra g), afirma que "la experiencia comparada muestra que existen otros criterios que prestan utilidad para determinar el carácter abusivo de una cláusula, por ejemplo, la

\footnotetext{
57 SERNAC CON INMOBILIARIA LAS ENCINAS (2014), considerando noveno; SERNAC CON CRÉDITOS ORGANIZACIÓN Y FINANZAS S.A. (2015), considerando decimotercero.

58 SERNAC CON TiCKETMASTER CHILE S.A. (2016), sentencia de nulidad, considerandos undécimo, decimosegundo y decimotercero.

59 SeRnaC con TiCKetmaster Chile S.A. (2016), sentencia de nulidad, considerando undécimo. En cuanto a la autorización para utilizar la información recolectada con fines comerciales, la Corte añade que la condición resulta contraria al inciso segundo del artículo 3 de la ley 19.628, que establece que "el titular puede oponerse a la utilización de sus datos personales con fines de publicidad, investigación de mercado o encuestas de opinión" (SERNAC CON TICKETMASTER CHILE S.A. (2016), sentencia de nulidad, considerando decimotercero).
} 
fuerza de las posiciones negociales del proveedor y el consumidor, el hecho que el consumidor haya sido inducido por el proveedor a celebrar el contrato o que los bienes y servicios hayan sido provistos al consumidor por orden de este, la naturaleza de los bienes y servicios y las demás cláusulas del contrato o de otros contratos"60.

Una aproximación diversa puede observarse en sentencia de 25 de julio de 2016, en que la Corte de Apelaciones de Santiago afirma la validez de una cláusula que faculta a Ticketmaster Chile S.A. para retener el cargo por servicio en caso de que se suspenda o cancele el evento para el cual ha sido adquirida una entrada dado que "el usuario lo sabe desde el primer momento - esto es que en caso de suspensión o cancelación del evento no se le devolverá el cargo por servicio- y aun así compra el ticket" ${ }^{11}$. Sin pronunciarnos respecto al equilibrio o desequilibrio de la cláusula enjuiciada ${ }^{62}$, el problema del criterio de la sentencia es que asume que el control resguarda una adecuada formación del consentimiento -y, sobre todo, la libertad de elección-, siendo que su finalidad es tutelar que las cláusulas no negociadas no incurran en un desequilibrio normativo significativo.

El mismo problema se advierte en sentencia de 23 de febrero de 2018, de la Corte de Apelaciones de Temuco. En el marco de un mutuo hipotecario y a propósito de una cláusula que faculta al Banco para acelerar el crédito en caso de que la deudora incurra en alguna de las prohibiciones acordadas -entre las que se encuentra una prohibición de enajenar el inmueble hipotecado-, la Corte sostiene que "no resulta posible establecer la "nulidad de la obligación" como se ha pedido por vía de declarar abusiva la cláusula décimo octava del contrato en análisis, con mayor razón si aun tratándose de un contrato de adhesión, la deudora ha concurrido con su voluntad a la suscripción del mismo, ha tenido acceso al contenido del contrato, y ha optado, también voluntariamente, por infringir durante el desarrollo del contrato, las condiciones establecidas en el mismo por el acreedor, para la seguridad de su crédito, como son la de no caer en mora de obligaciones crediticias y la facultad de acelerar el pago de su acreencia si ve peligrar el rescate de las garantías que acceden a la obligación principal"63. Cabe señalar que, con fecha 24 de septiembre de 2018 , la Corte Suprema, conociendo de un recurso de casación intentado en contra de la sentencia, sin examinar el equilibrio o desequilibrio de la cláusula, también justifica su validez bajo la

\footnotetext{
60 SERNAC CON TICKET FACIL S.A. (2018), sentencia de nulidad, considerando décimo.

61 SernaC CON TiCKetMaster CHILE S.A. (2016), considerando vigésimo.

${ }^{62} \mathrm{La}$ Corte Suprema anula la sentencia referida, apreciando la abusividad de la cláusula en razón de que el contrato impone al consumidor "la carga de soportar la pérdida de parte del precio de la venta de entrada a un evento que no se realiza, hecho respecto del cual el consumidor no tiene ninguna injerencia o responsabilidad; la demandada percibe, pues, ese valor mientras el consumidor nada recibe a cambio. En estas condiciones, es la parte más débil de la relación de consumo la que resulta gravada o afectada objetivamente pues no recibió el servicio esperado con la contratación" (SERNAC CON TICKETMASTER CHILE S.A. (2018), sentencia de nulidad, considerando decimoquinto). En rigor, la Corte aprecia la abusividad a la luz de la significación que el contrato tiene para un consumidor medio, estimando que "según él las partes son dos; él solo tiene al frente a un sujeto con el que negocia; desconoce las relaciones internas que puede haber tras el que aparece como vendedor; no tiene la intención ni el interés, ni le es permitido, entrar a averiguar la efectiva distribución de utilidades y riesgos entre los que intervienen en el espectáculo; por tanto, él da lo suyo: un valor total por un espectáculo; si no lo recibe, salvo situaciones extremas que no vienen al caso, habrá de ser restituido en lo que dio" (SERNAC CON TICKETMASTER CHILE S.A. (2018), sentencia de nulidad, considerando decimoquinto).

${ }^{63}$ BANCO SANTANDER CHILE S.A. CON VERDUGO (2018a), considerando quinto.
} 
premisa, ciertamente discutible, de que no entraba la circulación del inmueble hipotecado, sino que se limita a generar una obligación de no hacer ${ }^{64}$.

Con todo, en el último tiempo se advierte un cambio de paradigma en la jurisprudencia. En sentencias de 29 de noviembre de 2018 y 29 de agosto de 2019, la Corte Suprema sostiene que "la consideración del carácter abusivo de una cláusula contractual es una cuestión que importa una apreciación sobre el contenido de la estipulación en cuanto a la extensión de las prerrogativas que confiere a una de las partes y posición en que coloca o puede colocar a la contraparte. Esa evaluación no requiere necesariamente la prueba de una situación de abuso real y concreto, bastando para el juzgamiento la posibilidad de que la articulación valide una posición de abuso exorbitante con correlativo riesgo de detrimento y subordinación de la contraparte débil. Por ello, cada cláusula cuestionada es examinada en su contenido, evaluándose el espacio o ámbito de acción que entrega a las partes -que puede ser razonable y plausible atendidas las características de la relación- o, por el contrario, exorbitante y desmedido, generando el consiguiente riesgo de desmedro injusto de los derechos de la contraparte" ${ }^{65}$. Si la apreciación recae directamente sobre el contenido, sin considerar las circunstancias que pueden constituir un abuso real y concreto, entonces la apreciación es abstracta.

A mayor abundamiento, en sentencias de 9 de abril de 2018, 15 de abril de 2019 y 27 de diciembre de 2019, la Corte Suprema, luego de afirmar que basta la existencia de un desequilibrio importante para apreciar la abusividad, precisa que "el desequilibrio puede ser concretado en diversos ámbitos del contrato y, por lo mismo, terminan con diverso contenido: a) Confieren derechos exorbitantes al proponente, como las que le otorgan facultades de fijar o modificar elementos del contrato (como cambiar el precio, el tipo de producto o servicio o su régimen jurídico); b) Excluyen o restringen derechos de los consumidores, como las que imponen renuncias al ejercicio de acciones judiciales, reducen los medios de prueba, alteran la carga de la prueba; c) Reducen las obligaciones del predisponente, como la exoneración o restricción de su responsabilidad por incumplimiento o cumplimiento defectuoso; d) Imponen al consumidor cargas desproporcionadas, como pagar gravosas indemnizaciones o establecer plazos excesivamente breves para reclamos" ${ }^{66}$. Si se observa bien, las concreciones de desequilibrio notable e injustificado no son sino hipótesis genéricas de desviación ostensible del derecho dispositivo, las cuales se pueden apreciar sin necesidad de atender a las circunstancias concurrentes a la celebración del contrato.

Ahora bien, la línea abierta por sentencia de 29 de noviembre de 2018 no implica que las circunstancias concurrentes a la celebración del contrato no puedan configurar, en el caso particular, una situación de abuso que justifique la apreciación de abusividad de alguna cláusula; después de todo, la Corte no afirma que sea impertinente la acreditación de una situación de abuso real y concreto, sino que no resulta necesaria.

\footnotetext{
64 BANCO SANTANDER CHILE S.A. CON VERDUGO (2018b), considerando vigésimo.

65 SERNAC CON BANCO BBVA (2018), sentencia de nulidad, considerando decimoséptimo; ASOCIACIÓN DE CONSUMIDORES DE TARAPACA CON BANCO SANTANDER CHILE (2019), considerando undécimo.

66 SERNAC CON TICKETMASTER CHILE S.A. (2018), sentencia de nulidad, considerando duodécimo; SERNAC CON CORPORACION EDUCACIONAL UNIVERSIDAD DEL MAR (2019), sentencia de nulidad, considerando séptimo; SERNAC CON Constructora Santa Beatriz S.A. (2019), sentencia de nulidad, considerando séptimo.
} 
Otra sentencia que merece ser destacada es la de 9 de abril de 2019, de la Corte de Apelaciones de Arica. La Corte, a propósito de algunas cláusulas de un contrato de transporte aéreo que impedían solicitar cambio o devolución del dinero y que establecían la cancelación automática, sin derecho a reembolso, del segundo trayecto de un vuelo de dos tramos en caso de que no el pasajero no embarcara para el primero, afirma que "la expectativa sensata del querellante al contratar un transporte de ida y vuelta, era la posibilidad cierta de efectuar ambos viajes, independientemente que razones personales le permitieran efectuar uno de ellos, teniendo presente que la finalidad del contrato de transporte es precisamente la realización del transporte aéreo contratado, conforme se desprende de los artículos 133 y siguientes del Código Aeronáutico, y la omisión por parte del querellado de un actuar de buena fe, provoca en el contrato una manifiesta falta de reciprocidad en las obligaciones y derechos de ambos contratantes, con un desequilibrio importante para una de ellas, desde que sin comprobar una justificación técnica se exime de cumplir con la obligación contratada de trasporte, lo que impide la existencia de un justo equilibrio de las contraprestaciones, generando en consecuencia una cláusula abusiva a la que debe privarse de validez, en cuanto ella supone el pago de una prestación que no se realiza, provocando un enriquecimiento sin causa contrario al ordenamiento jurídico, motivo por el cual resulta irrelevante que esa cláusula fuera informada, dado que se inserta en un contrato de adhesión donde la ley ha facultado su examen en los términos ya explicados, por encontrase disminuida la capacidad de negociación de una las partes" ${ }^{67}$. Esta sentencia explicita que la información entregada, aun siendo oportuna, veraz y suficiente, no tiene la virtud de evitar la apreciación de abusividad de las cláusulas que introduzcan al contrato un desequilibrio normativo importante. Contra esta sentencia se interpuso recurso de queja, el cual fue rechazado ${ }^{68}$.

Haciendo un balance general, se puede afirmar que los tribunales superiores de justicia no solo aprecian la abusividad a la luz de los parámetros abstractos establecidos en la letra g) del artículo 16 de la LPDC, sino también considerando las circunstancias concurrentes a la celebración del contrato. No obstante, sin rechazar la posibilidad de que dichas circunstancias eventualmente desempeñen algún rol, en el último tiempo la jurisprudencia ha precisado que no es imprescindible su consideración para la apreciación de abusividad de las cláusulas que introduzcan desequilibrios normativos importantes. La mentada precisión se acopla de mejor manera a la evolución dogmática que existe sobre la materia.

\section{COLOFÓN}

En nuestra opinión, aunque se estimara que la remisión de la letra g) del artículo 16 de la LPDC a la finalidad del contrato implica la consideración no solo de las expectativas del adherente que están resguardadas por las reglas de derecho dispositivo, sino también de las expectativas que se ha forjado sobre la base de la información y la publicidad precontractual -incardinándose entonces el control de sorpresividad en el de contenido-, es necesario cuidarse de no acercar en demasía la apreciación de abusividad a la constatación del cumplimiento o incumplimiento de deberes de información, pues la entrega de la mejor y

\footnotetext{
${ }^{67}$ FAJARDO CON LATAM AILINES GROUP S.A. Y DESPEGAR. COM S.A. (2019), considerando quinto.

68 Despegar. com S.A. contra segunda sala de la Corte de Apelaciones de Arica (2019).
} 
más completa información no es suficiente para justificar la eficacia de una cláusula que no haya superado una apreciación abstracta de abusividad, ni siquiera en aquellos casos en que el contenido de esta sea de fácil comprensión para un adherente de diligencia ordinaria ${ }^{69}$. En este sentido, la consideración de las expectativas forjadas sobre la base de la información y la publicidad precontractual solamente podría servir como una medida adicional de protección para el adherente, justificando la apreciación de abusividad, a la luz de la referida letra g), de aquellas cláusulas que, aun sin desviarse ostensiblemente del derecho dispositivo, provocan una defraudación de las mentadas expectativas ${ }^{70}$. Esto podría resultar consistente con una visión realista del contrato ${ }^{71}$, conforme con la cual la finalidad del contrato estaría determinada, al menos en parte, por los intereses que un adherente de diligencia de ordinaria, en función de la información, de la publicidad y de las demás circunstancias concurrentes, espera satisfacer con la ejecución del programa contractual. Asimismo, tal aproximación podría cohonestarse de mejor manera con el imperativo de conceder una tutela reforzada a los consumidores vulnerables, es decir, a aquellos consumidores que, por su edad, condiciones médicas, falta de experiencia u otras razones, tengan un comportamiento económico especialmente susceptible de distorsión mediante prácticas comerciales desleales $^{72}$. Con todo, el control de sorpresividad, dogmáticamente más cercano al control de incorporación que al de contenido, podría fundarse en otras reglas de nuestro ordenamiento. En efecto, tal como se ha sostenido en derecho comparado, una concreción del control de sorpresividad puede fundarse en las reglas sobre integración de la publicidad al contrato $^{73}$. Según el artículo 1 No 4 de la LPDC, se entienden "incorporadas al contrato las condiciones objetivas contenidas en la publicidad hasta el momento de celebrar el contrato". Tales condiciones objetivas son las mencionadas por el artículo 28 de la ley, destacando especialmente la "idoneidad del bien o servicio para los fines que se pretende satisfacer y que haya sido atribuida en forma explícita por el anunciante"; "las características relevantes del bien o servicio destacadas por el anunciante"; "el precio del bien o tarifa del servicio, su forma de pago y el costo del crédito en su caso, en conformidad a las normas vigentes"; y "las condiciones en que opera la garantía". En esta línea, dado que, a la luz del artículo 12 de la LPDC, el profesional debe cumplir los términos, condiciones y modalidades convenidas con el consumidor o micro o pequeña empresa para la entrega del bien o la prestación del servicio, toda cláusula que se desvíe de las condiciones objetivas de la publicidad solo producirá efectos en la medida de que sea más beneficiosa para el adherente ${ }^{74}$. Por su parte, en caso de que no exista publicidad y que la defraudación de las expectativas del adherente se haya producido por falta de información o por la falta de adecuación del contenido predispuesto con la información entregada, las cláusulas en cuestión deberán estimarse no

\footnotetext{
69 En rigor, la comprensibilidad de una cláusula solo implica la superación de una carga de incorporación (TAPia y VAldivia (1999) pp. 70-73, BarRientos (2018) pp. 1012-1015).

70 Pagador (1998) pp. 72-74.

$71 \mathrm{Al}$ respecto, véase, por ejemplo, BRANTT (2011) pp. 47-50

72 Entre nosotros, refiriendo la categoría de consumidor vulnerable, López (2018) p. 111, nota al pie No 62.

73 Pagador (1999) pp. 491-498.

74 Pagador (2011) pp. 1363-1367, Campos (2019) pp. 287-291
} 
consentidas y, por tanto, nulas absolutamente ${ }^{75}$. En efecto, la falta de consentimiento configurará la causal genérica de nulidad absoluta contemplada en el artículo 1682 del Código Civil, consistente en la omisión de un requisito o formalidad que la ley exige para el valor en atención a la especie o naturaleza del acto o contrato ${ }^{76}$. No es óbice a esta nulidad el deber del adherente de informarse responsablemente de las condiciones de contratación (ex artículo 3 letra b) de la LPDC), pues tal deber ha de cumplirse a la luz de la información entregada por el propio proveedor, que es quien debe velar por la previsibilidad razonable del clausulado ${ }^{77}$. A mayor abundamiento, cabe descartar que la ausencia o deficiencia de información configure una hipótesis de error o dolo, pues si una cláusula no resulta razonablemente previsible para un adherente de diligencia ordinaria no puede reputarse siquiera presuntivamente consentida; en este sentido, la representación de los alcances económicos y jurídicos del contrato que el profesional haya provocado en el adherente se transforma en definitiva, y en contra de los planes del primero, en el auténtico y único contenido del contrato, sin que pueda hablarse propiamente de una falsa representación de la realidad. Por lo demás, desde una perspectiva consecuencialista, la nulidad relativa de la cláusula, esto es, su anulabilidad por error o dolo presenta diversos inconvenientes para el adherente: así, por ejemplo, la carga de la prueba -destacadamente intrincada cuando de dolo se trata-; la posibilidad de que un juez poco atento estime que la ejecución voluntaria de la obligación en los términos previstos en la cláusula sorpresiva implica una confirmación tácita; y el saneamiento por el transcurso de cuatro años contados desde la celebración del contrato ${ }^{78}$.

\section{CONCLUSIONES}

1. En la tradición alemana el control de sorpresividad se enmarca en el control de incorporación y para su superación debe examinarse si la condición general sometida a examen resulta previsible para un adherente de diligencia ordinaria a la luz de la información entregada por el profesional, la publicidad y las demás circunstancias concurrentes a la celebración del contrato. Por su parte, el control de contenido es eminentemente abstracto, no tiene en consideración las circunstancias concurrentes a la celebración del contrato, y se orienta a resguardar cierta medida de equilibrio en el contenido normativo de las condiciones generales.

2. La Directiva 93/13/CEE, optando por prescindir de un auténtico control de incorporación, establece en su artículo 4.1 tres parámetros de apreciación que concretizan el

\footnotetext{
75 Campos (2019) pp. 287-291. La ineficacia de las cláusulas que se aparten de la información entregada se sustenta justamente en que tal información se ha incorporado al contenido del contrato, no pudiendo ser desvirtuada por una cláusula que no sea razonablemente previsible.

76 Alessandri (1949) pp. 238 y 239. La nulidad absoluta afectará únicamente a la cláusula o estipulación abusiva, subsistiendo el resto del contrato en la medida que sea posible aún satisfacer las legítimas expectativas del adherente. Según doctrina nacional autorizada, la nulidad regulada en el Código Civil puede ser parcial incluso más allá de los casos expresamente contemplados en tal cuerpo legal (TAPiA y VALdivia (1999) p. 165, DomínGUEZ (2016) pp. 183 y 184).

77 Como afirma De la Maza, el deber de informar es del proveedor. El adherente solo tiene una carga que ha de observar en su propio interés a la luz de la información que se le ha suministrado (DE LA MAZA (2010) p. 37).

78 Campos (2019) pp. 289 y 290. Sobre estos tópicos, Pertínez (2004) pp. 213 y 214.
} 
control de contenido. Entre estos parámetros se encuentra la consideración de las circunstancias concurrentes a la celebración del contrato, lo que implica una incardinación del control de sorpresividad en el de contenido. Con todo, según un entendimiento generalizado, la mentada incardinación debe implicar una medida de tutela adicional al consumidor, de modo que la información entregada respecto al contenido, sentido y alcance de una cláusula no negociada, por muy adecuada que sea, no impide que la cláusula sea apreciada como abusiva si entraña un desequilibrio importante en el contenido normativo del contrato; por el contrario, la mentada incardinación permite apreciar la abusividad de cláusulas que, sin introducir desequilibrio importantes, defraudan las expectativas que un consumidor de diligencia ordinaria podría forjarse sobre la base de la información, publicidad y demás circunstancias concurrentes.

3. Pese a que la LPDC contempla tanto un control de incorporación como uno de contenido y que, respecto a este último, el artículo 16 letra g) de la LPDC consagra parámetros de apreciación abstracta, parte de la doctrina nacional tiende a acercar el control de contenido a uno de sorpresividad, lo que entraña el riesgo de justificar la validez de cláusulas que establecen desequilibrios normativos significativos por mor de la información entregada por el profesional.

4. Nuestros tribunales superiores de justicia tienden a incardinar el control de sorpresividad en el de contenido, sin perjuicio de que en el último tiempo se ha puesto de relieve que un juez puede prescindir por entero de las circunstancias concurrentes a la celebración del contrato para efectos de apreciar la abusividad de una cláusula.

5. A fin de que el control de contenido no sea vulgarizado, el control de sorpresividad puede fundarse en otras reglas de la LPDC y del Código Civil. En concreto, en caso de que la sorpresividad de una cláusula se configure por su falta de adecuación a las condiciones objetivas de publicidad, la ineficacia puede fundarse en la integración de estas condiciones objetivas al contenido del contrato y la fuerza obligatoria de este, todo ello a la luz de los artículos $1^{\circ}$ No 4, 12 y 28 de la LPDC. Por su parte, en caso de que la sorpresividad se configure por la falta de adecuación del contenido predispuesto con la demás información precontractual entregada por el profesional, las cláusulas en cuestión pueden estimarse no consentidas y, por tanto, nulas absolutamente, en conformidad con la causal genérica de nulidad absoluta contemplada en el artículo 1682 del Código Civil.

\section{BIBLIOGRAFÍA CITADA}

Albanese, Antonio (2013): "Le clausole vessatorie nel diritto europeo dei contratti", Europa e Diritto privato, No 3: pp. 669-728.

Albiez, Klaus (2002): "Un nuevo derecho de obligaciones. La reforma 2002 del BGB", Anuario de Derecho Civil, No 3: pp. 1133-1228.

Albiez, Klaus (2009): La protección jurídica de los empresarios en la contratación con condiciones generales (Pamplona, Aranzadi).

Alessandri, Arturo (1949): La nulidad y la rescisión en el derecho civil chileno (Santiago, Imprenta Universitaria). 
Alfaro, Jesús (1991): Las condiciones generales de la contratación. Estudio de las disposiciones generales (Madrid, Civitas).

BALlesteros, José (1999): Las condiciones generales de los contratos y el principio de la autonomía de la voluntad (Barcelona, José María Bosch Editor).

BARCiA, Rodrigo (2016): "Análisis de la letra g) del artículo 16 de la ley de protección de los derechos de los consumidores a la luz de la jurisprudencial", en Vivanco, Ángela et al. (autores), Anuario de doctrina y jurisprudencia. Sentencias destacadas 2016. Una mirada desde la perspectiva de las políticas públicas (Santiago, Ediciones Lyd) pp. 103-119.

Barrientos, Francisca (2018): "Repensando el control de forma de los contratos por adhesión: una mirada a su aplicación actual y la introducción de la transparencia”, en BAHAmondes, Claudia, Etcheberry, Leonor y Pizarro, Carlos (editores), Estudios de derecho civil XIII. Ponencias presentadas en las XV Jornadas Nacionales de Derecho Civil (Santiago, Thomson Reuters) pp. 1001-1018.

Ben-Shahar, Omri (2008): "The myth of the 'opportunity to read' in contract law", Olin Working Paper, No 415, University of Chicago Law \& Economics: pp. 1-28.

Bianca, Massimo (2000): Il contratto (Milano, Giuffrè Editore S.p.A., segunda edición).

Blandino, María (2012): "Capítulo 9. Contenido y efectos de los contratos", en Vaquer, Antoni, Bosch, Esteve y SÁnchez, María (coordinadores), Derecho europeo de los contratos. Libros II y IV del marco común de referencia (Barcelona, Atelier) pp. 573-694.

BRANTT, María Graciela (2011): "El caso fortuito: concepto y función como límite de la responsabilidad contractual”, en DE LA MAZA, Íñigo (coordinador), Incumplimiento contractual. Nuevas perspectivas (Santiago, Ediciones Universidad Diego Portales) pp. 47-82.

CÁmara, Sergio (2006): El control de las cláusulas «abusivas» sobre elementos esenciales del contrato (Navarra, Aranzadi).

Campos, Sebastián (2019): Control de contenido y régimen de ineficacia de las cláusulas abusivas (Santiago, Thomson Reuters).

Carballo, Marta (2010): "Las cláusulas contractuales no negociadas ante la Propuesta de Directiva de derechos de los consumidores", InDret Revista para el Análisis del Derecho, No 1: pp. 1-28.

Carrasco, Ángel (2017): Derecho de contratos (Navarra, Aranzadi Thomson Reuters, segunda edición actualizada y revisada).

Carvajal, Patricio (2011): "Tipicidad contractual y derecho de los consumidores. Artículo 16 letra G) de la ley No 19.496", en elorriaga, Fabián (coordinador), Estudios de Derecho Civil VII (Viña del Mar, Editorial Legal Publishing) pp. 441-448.

CONTARDO, Juan Ignacio (2014): "Ensayo sobre el requisito de la escrituración y sus formas análogas en los contratos por adhesión regidos por la ley No 19.496”, en BARRIENTOS, Francisca (coordinadora), Condiciones generales de la contratación y cláusulas abusivas (Santiago, Ediciones Universidad Diego Portales) pp. 113-127.

De la MaZA, Íñigo (2004): "El control de las cláusulas abusivas y la letra g)", Revista chilena de Derecho privado, No 1: pp. 1-25.

De la MaZA, Íñigo (2010): "El suministro de información como técnica de protección de los consumidores: los deberes precontractuales de información”, Revista de Derecho (UCN), No 2: pp. 21-52. 
De la Maza, Íñigo (2014): “¿Pero qué es lo que esperabas? Contratos por adhesión y expectativas razonables", en Turner, Susan y Varas, Juan (coordinadores), Estudios de Derecho Civil IX (Santiago, Thomson Reuters) pp. 333-350.

De la Maza, Íñigo y Momberg, Rodrigo (2018): "La transparencia como mecanismo de tutela de la privacidad de los consumidores y usuarios en contratos electrónicos”, Revista chilena de derecho y tecnología, No 2: pp. 81-111.

Díaz, Silvia (2000): "Artículo 6. Reglas de interpretación", en BerCovitz, Rodrigo (coordinador), Comentarios a la Ley de Condiciones Generales de la Contratación (Navarra, Aranzadi) pp. 193-232.

Domínguez, Ramón (2016): Teoría General del Negocio Jurídico (Santiago, Editorial Jurídica, segunda edición actualizada).

Ebers, Martin (2016): Obligaciones, Contratos y Protección del Consumidor en el Derecho de la Unión Europea y los Estados Miembros (Santiago, Ara Editores).

FARNETI, Marcello (2009): La vessatorietà delle clausole principali nei contratti del consumatore (Padova, CEDAM).

GonZÁlez, Isabel (2000a): "Artículo 5. Requisitos de incorporación”, en Bercovitz, Rodrigo (coordinador), Comentarios a la Ley de Condiciones Generales de la Contratación (Navarra, Aranzadi) pp. 139-192.

GonZÁlez, Isabel (2000b): “Artículo 7. No incorporación”, en BerCovitZ, Rodrigo (coordinador), Comentarios a la Ley de Condiciones Generales de la Contratación (Navarra, Aranzadi) pp. 235-258.

GonZÁlez, Isabel (2015): "Art. 82. Concepto de cláusulas abusivas", en BerCovitZ, RODRIGo (coordinador), Comentario del Texto Refundido de la Ley General para la Defensa de los Consumidores y Usuarios y otras leyes complementarias (Navarra, Aranzadi Thomson Reuters, segunda edición) pp. 1103-1145.

Loewenstein, George y O'Donoghue, Ted (2006): "We can do this the easy way or the hard way: Negative emotions, self-regulation, and the law", The University of Chicago Law Review, No 73: pp. 183-206.

López, Patricia (2018): "Por una modulación reequilibradora del ámbito de aplicación subjetivo de la ley 19.496: su expansión a las tratativas preliminares y al período de prueba del bien o producto y su improcedencia frente al abuso del consumidor", Revista de Derecho (Concepción), No 244: pp. 91-127.

LorenZinI, Jaime y Polit, Joaquín (2013): "El régimen de la nulidad y la resolución en el derecho del consumidor chileno", en Domínguez, Carmen, González, Joel, Barrientos, Marcelo y GoldenberG, Juan (coordinadores), Estudios de Derecho Civil VIII (Santiago, Editorial Legal Publishing) pp. 465-480.

MomberG, Rodrigo (2012): "La transformación de la ley de protección de los derechos de los consumidores en la norma común del derecho de contratos chileno", en ElorRIAGA, Fabián (editor), Estudios de Derecho Civil VII (Santiago, Editorial Lexis-Nexis) pp. 377-391.

Momberg, Rodrigo y Pizarro, Carlos (2013): “Artículo 16 g)", en De La Maza, Íñigo y Pizarro, Carlos (directores) y Barrientos, Francisca (coordinadora), La protección de los derechos de los consumidores (Santiago, Legal Publishing) pp. 340-351. 
Morales, María (2018): Control preventivo de cláusulas abusivas (Santiago, Editorial DER Ediciones Limitada).

Morales, María y Veloso, Franco (2019): “Cláusulas abusivas en la Ley No 19.496. Ley, doctrina y jurisprudencia”, en Morales, María (directora) y Mendoza, Pamela (coordinadora), Derecho del consumo. Ley, doctrina y jurisprudencia (Santiago, Editorial DER Ediciones Limitada) pp. 149-167.

Pagador, Javier (1998): La Directiva Comunitaria sobre las Cláusulas Contractuales Abusivas (Madrid, Marcial Pons).

PAGADOR, Javier (1999): Las condiciones generales y cláusulas contractuales predispuestas. La ley de condiciones generales de contratación (Barcelona, Marcial Pons).

Pagador, Javier (2011): “Condiciones generales y cláusulas abusivas”, en Rebollo, Manuel e IzQUiERDo, Manuel (directores), La defensa de los consumidores y usuarios (comentario sistemático del Texto Refundido aprobado por Real Decreto Legislativo 1/2007) (Madrid, Iustel) pp. 1306-1442.

PatTi, Salvatore y PAтTI, Guido (1993): Responsabilità precontrattuale e contratti standard. Artt. 1337-1342 (Milán, Giuffrè).

Pertínez, Francisco (2004): Las cláusulas abusivas por un defecto de transparencia (Navarra, Aranzadi).

Pertíñez, Francisco (2013): "Falta de transparencia y carácter abusivo de la cláusula suelo en los contratos de préstamo hipotecario", InDret Revista para el análisis del derecho, No 3: pp. 1-28.

Pertínez, Francisco (2017): La nulidad de las cláusulas suelo en préstamos hipotecarios (Valencia, Tirant lo Blanch, segunda edición).

Pinochet, Ruperto (2019): "La razonabilidad como criterio de control del contenido en los contratos predispuestos", en BARRía, Manuel et al. (directores y coordinadores), Estudios de Derecho Privado. En Homenaje al Profesor Daniel Peñailillo Arévalo (Santiago, Thomson Reuters) pp. 495-514.

Pizarro, Carlos y Pérez, Ignacio (2013): “Artículo 17”, en De La Maza, Ínigo y Pizarro, Carlos (directores) y Barrientos, Francisca (coordinadora), La protección de los derechos de los consumidores. Comentarios a la Ley de Protección a los Derechos de los Consumidores (Santiago, Legal Publishing) pp. 359-363.

Rizzo, Vito (2013): "La disciplina delle clausole vessatorie: profili storici" en Belleldi, Alessandra, Mezzasoma, Lorenzo y Rizzo, Francesco (directores), Le clausole vessatorie a vent'anni dalla Direttiva CEE 93/13 (Napoli, Edizione Scientifiche Italiane) pp. 39-58.

SimOn, Herbert (1955): "A behavioral model of rational choice", Quarterly Journal of Economics, Vol. 69, No 1: pp. 99-118.

Sunstein, Cass y Thaler, Richard (2003): "Libertarian paternalism is not an oxymoron", The University of Chicago Law Review, Vol. 70, No 4: pp. 1159-1202.

Tapia, Mauricio y Valdivia, José (1999): Contrato por Adhesión. Ley No 19.496 (Santiago, Editorial Jurídica de Chile).

Zimmermann, Reinhard (2008): El nuevo derecho alemán de obligaciones. Un análisis desde la Historia y el Derecho comparado (trad. Esther Arroyo Amayuelas, Barcelona, Editorial Bosch S.A.). 


\section{NORMAS CITADAS}

1. NORMATIVA NACIONAL.

LEY No 19.496 (7/3/1997), establece Normas sobre Protección de los Derechos de los Consumidores.

Ley No 19.955 (14/7/2004), modifica la ley No 19.496 sobre Protección de los Derechos de los Consumidores.

LEY No 20.416 (3/2/2010), fija normas especiales para las empresas de menor tamaño.

Decreto con Fuerza de Ley No 1 (16/5/2000), que fija el texto refundido, coordinado y sistematizado del Código Civil chileno.

2. NORMATIVA INTERNACIONAL, EXTRANJERA E INSTRUMENTOS DE DERECHO UNIFORME.

BÜrgerliches Gesetzbuch - BGB (Alemania).

Code de la consommation (Francia).

Codice Civile (Italia).

Codice del Consumo (Italia).

Texto Refundido de la ley General para la Defensa de Consumidores y Usuarios (España) - TRLGDCU

DireCtiva 93/13/CEE (21/4/1993), del Consejo, sobre las cláusulas abusivas en los contratos celebrados con consumidores.

ACQUIS PRINCIPLES - ACQP.

DRAFT COMMON FRAME OF REFERENCE -DCFR.

Principles of EUROPEAN CONTRACT LAW -PECL.

\section{JURISPRUDENCIA CITADA}

Mohamed Aziz contra CaiXa d'Estalvis de Catalunya, Tarragona i Manresa (CatalunyaCAIXA) (2013): Tribunal de Justicia de la Unión Europea, 14 de marzo de 2013 (Cuestión prejudicial de interpretación). Asunto C-415/11. Disponible en http://curia.europa.eu/juris/recherche.jsf?language $=$ es [fecha visita 24 de enero de 2020].

KÁsLer y KASLERNÉ Rabai CONTRA OTP JELZALOGBANK ZRT (2014): Tribunal de Justicia de la Unión Europea, 30 de abril de 2014 (Cuestión prejudicial de interpretación). Asunto C-26/13. Disponible en http://curia.europa.eu/juris/recherche.jsf?language=es [fecha visita 24 de enero de 2020].

Bogdan Matei Y Joana Ofelia Matei contra SC VOLKSBANK RomÂnia SA (2015): Tribunal de Justicia de la Unión Europea, 26 de febrero de 2015 (Cuestión prejudicial de interpretación). Asunto C-143/13. Disponible en http://curia.europa.eu/juris/recherche. jsf?language $=\mathrm{es}$ [fecha visita 24 de enero de 2020].

Camus con Comercializadora Alto Manatagua S.A. (2007): Corte de Apelaciones de Santiago, 21 de septiembre de 2007 (acción en defensa del interés individual del consumidor). Rol 3746-2007. Disponible en http://www.pjud.cl/consulta-unificada-de-causas [fecha visita 24 de enero de 2020]. 
HubNer y JuÁrez con UNIVERSIDAd MAYOR (2008): Corte de Apelaciones de Santiago, 1 de julio de 2008 (acción en defensa del interés individual del consumidor). Rol 87752004. Disponible en http://www.pjud.cl/consulta-unificada-de-causas [fecha visita 24 de enero de 2020].

ParRa con Universidad AndRÉs Bello (2008): Corte de Apelaciones de Santiago, 5 de julio de 2008 (acción en defensa del interés individual del consumidor). Rol 2335-2008. Disponible en http://www.pjud.cl/consulta-unificada-de-causas [fecha visita 24 de enero de 2020].

RAVINET CON UNIVERSIDAD ANDRÉS BELLO (2012): Corte de Apelaciones de Santiago, 14 de mayo de 2012 (acción en defensa del interés individual del consumidor). Rol 19052011. Disponible en http://www.pjud.cl/consulta-unificada-de-causas [fecha visita 24 de enero de 2020].

SERNAC CON CENCOSUD (2013): Corte Suprema, 24 de abril de 2013 (acción en defensa del interés colectivo y difuso de los consumidores). Rol 12355-2011. Disponible en http:// www.pjud.cl/consulta-unificada-de-causas [fecha visita 24 de enero de 2020].

SERNAC CON INMOBILIARIA LAS ENCINAS (2014): Corte de Apelaciones de Santiago, 3 de junio de 2014 (acción en defensa del interés colectivo y difuso de los consumidores). Rol 8281-2013. Disponible en http://www.pjud.cl/consulta-unificada-de-causas [fecha visita 24 de enero de 2020].

SERNAC CON CRÉDITOS ORGANIZACIÓN Y FINANZAS S.A. (2014): Vigesimosegundo Juzgado de Letras en lo Civil de Santiago, 18 de julio de 2014 (acción en defensa del interés colectivo y difuso de los consumidores). Rol C-1746-2012. Disponible en http://www.pjud. cl/consulta-unificada-de-causas [fecha visita 24 de enero de 2020].

SERNAC CON CRÉDitos ORGANizaCión y Finanzas S.A. (2015): Corte de Apelaciones de Santiago, 13 de enero de 2015 (acción en defensa del interés colectivo y difuso de los consumidores). Rol 5992-2014. Disponible en http://www.pjud.cl/consulta-unificadade-causas [fecha visita 24 de enero de 2020].

SERNAC CON TiCKETMASTER CHILE S.A. (2016): Corte Suprema, 7 de julio de 2016 (acción en defensa del interés colectivo y difuso de los consumidores). Rol 1533-2015. Disponible en http://www.pjud.cl/consulta-unificada-de-causas [fecha visita 24 de enero de 2020].

Sernac con Ticketmaster Chile S.A. (2016): Corte de Apelaciones de Santiago, 25 de julio de 2016 (acción en defensa del interés colectivo y difuso de los consumidores). Rol 778-2016. Disponible en http://www.pjud.cl/consulta-unificada-de-causas [fecha visita 24 de enero de 2020].

Banco Santander Chile S.A. con Verdugo (2018a): Corte de Apelaciones de Temuco, 23 de febrero de 2018 (acción ejecutiva para cobro de pesos). Rol 887-2017. Disponible en http://www.pjud.cl/consulta-unificada-de-causas [fecha visita 24 de enero de 2020].

SERNAC CON TICKET FÁIL S.A. (2018): Corte Suprema, 7 de marzo de 2018 (acción en defensa del interés colectivo y difuso de los consumidores). Rol 79123-2016. Disponible en http://www.pjud.cl/consulta-unificada-de-causas [fecha visita 24 de enero de 2020].

SERNAC CON TiCKeTMASTer CHILE S.A. (2018): Corte Suprema, 9 de abril de 2018 (acción en defensa del interés colectivo y difuso de los consumidores). Rol 62158-2016. Dispo- 
nible en http://www.pjud.cl/consulta-unificada-de-causas [fecha visita 24 de enero de 2020].

Banco Santander Chile S.A. Con Verdugo (2018b): Corte Suprema, 24 de septiembre de 2018 (acción ejecutiva para cobro de pesos). Rol 6544-2018. Disponible en http:// www.pjud.cl/consulta-unificada-de-causas [fecha visita 24 de enero de 2020].

SERNAC CON BANCO BBVA (2018): Corte Suprema, 29 de noviembre de 2018 (acción en defensa del interés colectivo y difuso de los consumidores). Rol 100759-2016. Disponible en http://www.pjud.cl/consulta-unificada-de-causas [fecha visita 24 de enero de 2020].

Fajardo con Latam Ailines GRoup S.A. y Despegar.com S.A. (2019): Corte de Apelaciones de Arica, 9 de abril de 2019 (acción en defensa del interés individual del consumidor). Rol 16-2019. Disponible en http://www.pjud.cl/consulta-unificada-de-causas [fecha visita 24 de enero de 2020].

SERNAC CON CORPORACIÓN EDUCACIONAL UNIVERSIDAD DEL MAR (2019): Corte Suprema, 15 de abril de 2019 (acción en defensa del interés colectivo y difuso de los consumidores). Rol 5363-2018. Disponible en http://www.pjud.cl/consulta-unificada-de-causas [fecha visita 24 de enero de 2020].

Despegar.com S.A. CONTRA Segunda sala de la CoRte de Apelaciones de ARICA (2019): Corte de Suprema, 22 de agosto de 2019 (acción en defensa del interés individual del consumidor). Rol 9816-2019. Disponible en http://www.pjud.cl/consulta-unificada-decausas [fecha visita 24 de enero de 2020].

Asociación de consumidores de Tarapacá con Banco Santander Chile (2019): Corte Suprema, 29 de agosto de 2019 (acción en defensa del interés colectivo y difuso de los consumidores). Rol 8735-2018. Disponible en http://www.pjud.cl/consulta-unificadade-causas [fecha visita 24 de enero de 2020].

Sernac con Constructora Santa Beatriz S.A. (2019): Corte Suprema, 27 de diciembre de 2019 (acción en defensa del interés colectivo y difuso de los consumidores). Rol 1142019. Disponible en http://www.pjud.cl/consulta-unificada-de-causas [fecha visita 24 de enero de 2020]. considerando séptimo. 